\title{
HEAVY METALS IN HAIR SAMPLES: A PILOT STUDY OF ANAEMIC CHILDREN IN KAZAKHSTAN, KYRGYZSTAN AND UZBEKISTAN
}

\author{
Zuzana Derflerová Brázdová1, Joceline Pomerleau², Jindřich Fiala', Lenka Vorlová3, Dana Müllerová4 \\ ${ }^{1}$ Department of Preventive Medicine, Faculty of Medicine, Masaryk University, Brno, Czech Republic \\ ${ }^{2}$ Department of Health Services Research and Policy, London School of Hygiene and Tropical Medicine, London, United Kingdom \\ ${ }^{3}$ Faculty of Veterinary Hygiene and Ecology, University of Veterinary and Pharmaceutical Sciences Brno, Czech Republic \\ ${ }^{4}$ Department of Public Health, Medical Faculty in Pilsen, Charles University, Pilsen, Czech Republic
}

\section{SUMMARY}

Background: Heavy metals with their potential haematotoxic effect can contribute to the risks of anaemia in children in the Central Asian Republics (CAR), where burden and exposure to these metals is still not sufficiently known and reported.

Methods: Cross-sectional study was performed in Central Asian countries in hospitals in Kazakhstan, Kyrgyzstan and Uzbekistan with the aim to investigate the potential contribution of heavy metals to anaemia in children. In each country, 20 children were recruited, all were hospitalised with diagnosed anaemia. A sample of hair was taken from each child to assess the hair concentration of lead, cadmium and mercury.

Results: Relatively high levels of hair lead were observed, particularly in Kyrgyzstan. While lead and cadmium concentrations did not differ significantly among countries, mercury was lower in Kazakhstan than in Kyrgyzstan $(p<0.05)$ and Uzbekistan $(p<0.001)$. Hair lead and cadmium levels were significantly positively correlated (correlation coefficient $=0.51, p<0.001$ ).

Conclusion: The results of this study showed higher than expected levels of hair lead, cadmium and mercury in anaemic children. Because iron deficiency anaemia is a major public health problem in CAR, further investigation of the extent of exposure to heavy metal and its contribution in iron deficiency anaemia in the region would be recommended.

Key words: children, iron-deficiency anaemia, lead, cadmium, mercury

Address for correspondence: Z. Derflerová Brázdová, Department of Preventive Medicine, Faculty of Medicine, Masaryk University, Kamenice 5, 62500 Brno, Czech Republic. E-mail: brazdova@muni.cz

\section{INTRODUCTION}

Iron deficiency is one of the most common nutritional deficiencies worldwide (1) affecting $43 \%$ of the world's infants and children under the age of four years (2). Iron deficiency anaemia (IDA) has serious health consequences, including impaired cognitive and motor development in children, higher risk of maternal mortality, increased prenatal and perinatal mortality, and lowered capacity for physical activity, with its resulting consequences (3).

In Europe, about 7\% of the population suffer from iron deficiency anaemia but large variations exist among countries and sub-groups within countries. In the Central Asian Republics (CAR), the prevalence of anaemia is known to reach $50-69 \%$ in children below the age of three years (4), iron deficiency being the most likely cause of anaemia in the population. Very young children are at a particularly high risk of iron deficiency anaemia due to their rapid growth. If the dietary intake of iron cannot meet the increased needs of the children, iron deficiency anaemia may develop, particularly if the diet is poor in vitamin $\mathrm{C}$ and rich in inhibitors of iron absorption (such as phytates, tea, unmodified cow's milk and milk products introduced too early) (5).

It has been reported that the consumption of small amounts of lead can impair heme synthesis and compete with iron absorption, thus contributing to anaemia (5). This might be an important ag- gravating factor to consider in regions where environmental contamination with heavy metals is high, although little research has been done on this issue in Europe. This study examined the hair levels of lead, cadmium, and mercury in a sample of hospitalized anaemic children living in the CAR of Kazakhstan, Kyrgyzstan, and Uzbekistan.

\section{MATERIALS AND METHODS}

\section{Study Sample}

A sample of anaemic children from CAR was recruited for this pilot study. Girls were considered for inclusion only if their hair was short (length similar to that of boys). All children were hospitalised with anaemia diagnosed using the methods routinely employed by CAR (Gemosally) and using the cut-off points for haemoglobin recommended by the World Health Organization (110 g/L for children aged from 6 months to 5 years; $115 \mathrm{~g} / \mathrm{L}$ for those aged 5-11 years; $120 \mathrm{~g} / \mathrm{L}$ for those aged 12-13 years; 130 $\mathrm{g} / \mathrm{L}$ for older boys; $120 \mathrm{~g} / \mathrm{L}$ for older girls) (5). All children had clinical signs of anaemia, such as pale palms. Twenty children (9 boys, 11 girls) were recruited in Almaty in Kazakhstan, 20 (12 boys, 8 girls) in Osh in Kyrgyzstan, and 23 (12 boys, 8 girls) 
in Tashkent in Uzbekistan. The average age of the children was $9.9+4.2$ years (range $2-15$ ) in Kazakhstan, $2.8+1.0$ years (range 2-6) in Kyrgyzstan, and 2.6 + 1.0 years (range 1-5) in Uzbekistan. Ethical approval was obtained from the Masaryk University Ethics Committee. In each hospital, informed consent of parents of each child was obtained prior to recruitment to the study.

\section{Laboratory Analyses}

A small sample of hair (about 0.5 to $2.5 \mathrm{~g}$ ) was collected from each child according to WHO guidance (6) and kept in a paper envelope. Hair samples were washed in the system 'acetone-wateracetone-water-acetone'. This eliminated the possible influence of contaminants found in shampoo. After drying in laboratory temperature a specimen of $0.2000 \mathrm{~g}$ was taken from each sample. Decomposition was then made by microwave heating in a closed system (MILESTONE MLS 1200 MEGA, Italy) using the following conditions: sample $+3.0 \mathrm{ml} \mathrm{HNO}_{3}$ concentrated (MerckSuprapur) $+0.5 \mathrm{ml} \mathrm{H}_{2} \mathrm{O}_{2} 30 \%$ (Fluka p.a.), $300 \mathrm{~W}, 5$ minutes. The measurement of lead, cadmium and mercury was performed by the method of atomic absorption spectrometry with electrothermal atomization (SOLAAR 939 Atomic Absorption Spectrometer, GF 90, ATI Unicam, Cambridge, United Kingdom).

\section{Statistical Analyses}

Statistical analyses were performed using the statistical package STATA version 10 (Stata Corporation, College Station, Texas, USA). In six children, the mercury concentration was found to be below the detectable level of $0.02 \mu \mathrm{g} / \mathrm{g}$. For statistical purposes, these children were assigned a value of $0.01 \mu \mathrm{g} / \mathrm{g}$. Means, standard deviations (SD) and medians were estimated for each parameter. Differences among countries in hair level concentrations of lead, cadmium and mercury were assessed using analyses of variance and Bonferroni's multiple comparison tests after having statistically transformed the variables due to their non-normal distributions (square-root transformation of lead and mercury and log-normal transformation of cadmium). The relationship between lead and cadmium levels was assessed using Pearson correlation. Statistical significance was taken as $\mathrm{p}<0.05$.

\section{RESULTS AND DISCUSSION}

Median values obtained for each parameter are described in Table 1 . The overall median values were $6.82 \mu \mathrm{g} / \mathrm{g}$ for hair lead levels, $0.11 \mu \mathrm{g} / \mathrm{g}$ for hair cadmium levels, and $0.23 \mu \mathrm{g} / \mathrm{g}$ for hair mercury levels. In Kyrgyzstan, lead levels were generally higher than in Kazakhstan and Uzbekistan and haemoglobin levels tended to be lower, but differences did not reach statistical significance. There was no significant difference among countries for cadmium levels, but mercury levels were significantly higher in Kyrgyzstan and Uzbekistan than in Kazakhstan. Hair lead and cadmium levels were significantly positively correlated (correlation coefficient $=$ $0.51, \mathrm{p}<0.001)$.

In this study of anaemic children from Kazakhstan, Kyrgyzstan and Uzbekistan, the levels of hair lead were in several cases dramatically higher compared to what has been observed in historical studies of children of comparable age from Central and Eastern Europe. Spěváčková et al. (7), for example, observed that healthy Czech children aged 8 to 10 years had an average hair concentration of lead of $3.07 \mu \mathrm{g} / \mathrm{g}$, less than half the median level observed in this study $(6.81 \mu \mathrm{g} / \mathrm{g})$. Older data from areas of the former Federal Republic of Germany also showed lower mean hair lead concentrations in children aged 3 to 7 years, i.e., $3.7 \mu \mathrm{g} / \mathrm{g}$ in the industrialised area of Duisburg and $1.9 \mu \mathrm{g} / \mathrm{g}$ in the rural area of Westphalia (8). Our findings also indicated higher levels of hair lead than in children aged 10-11 years living in a polluted area of city of Chorzow in Poland (mean $=4.41 \mu \mathrm{g} / \mathrm{g}$ ) (9), but levels comparable to those of children aged $8-15$ years living in one of the areas of Poland most contaminated with heavy metal $($ mean $=8.21 \mu \mathrm{g} / \mathrm{g})(10)$. High levels of lead were found in children working or living close to open disposal sites in Bangladesh (11) and in people living in Mongolia (12). We can postulate that the high lead levels observed could be partly explained by an increased absorption of environmental lead associated with iron deficiency. Iron absorption is being increased when iron deficiency is present and the absorption of lead, which competes for absorption with iron using the same pathway, also tends to be increased. This in turn contributes to aggravating anaemia. This fact is confirmed for example by Rahman et al. (13) and Shah et al. (14) in studies conducted in Pakistan. However, it is also possible that a higher than expected exposure to environmental lead may have affected the children recruited for this study. All lived in large cities where non-unleaded gas (with tetraethyl lead) is used and can thus be suspected to be a source of environmental lead. Other environmental sources of lead such as the household plumbing system for water distribution, the type of paint used and other environmental sources of contamination should be investigated further in a targeted manner. Lead being a potential cause of mental retardation and behavioural problems in children, further research would be required to assess the extent of the problem in young children living in the region.

In addition to lead, the intake of cadmium and mercury are general health concerns throughout the world because of the potential toxicity of these heavy metals $(6,15,16)$. Although cadmium does not affect haematopoiesis, it is an indicator of a polluted food chain, as food in one of the principal environmental sources of cadmium. In the current context we also must take into account smoking as another major vector of cadmium exposure due to possible risk of passive smoking in households, what is mentioned by e.g. Chan et al. (17) in the study from Hong Kong or by Serdar et al. (18) from Turkey. And of course, traffic intensity is another possible vector of cadmium as an environmental pollutant, according to Hrubá et al. (19). In this pilot study, we observed a highly significant correlation between lead and cadmium levels, similar to the results of Goudarzi et al. (20) in Iran and Barton (21) in Poland. High levels of cadmium suggest in general that the food chain may have been contaminated by environmental pollutants. However, the median hair cadmium levels were relatively low compared with those reported by Spěváčková et al. (7), Kasznia-Kocot et al. (9) and Chłopicka et al. (10), who observed, respectively, mean hair cadmium levels of $0.44 \mu \mathrm{g} / \mathrm{g}$ in Czech children, $0.53 \mu \mathrm{g} / \mathrm{g}$ in children living in Chorzow (Poland), and $0.91 \mu \mathrm{g} / \mathrm{g}$ in children living in Miasteczko Slaskie (Poland). The hair concentration of mercury observed in the children also did not tend to exceed the usual levels found in other studies from the Czech Republic, Spain, China, Korea 
Table 1. Description of blood and hair parameters by country

\begin{tabular}{|c|c|c|c|}
\hline Parameter & $\begin{array}{c}\text { Kazakhstan } \\
n=20\end{array}$ & $\begin{array}{c}\text { Kyrgyzstan } \\
n=20\end{array}$ & $\begin{array}{c}\text { Uzbekistan } \\
n=20\end{array}$ \\
\hline \multicolumn{4}{|c|}{ Blood haemoglobin (g/L) } \\
\hline mean $\pm S D^{a}$ & $107 \pm 7$ & $95 \pm 3$ & $98 \pm 8$ \\
\hline Median & 110 & 95 & 98 \\
\hline Range & $90-115$ & $90-99$ & $76-115$ \\
\hline \multicolumn{4}{|l|}{ Hair lead ( $\mu \mathrm{g} / \mathrm{g})$} \\
\hline Median & 5.04 & 8.86 & 4.89 \\
\hline Range & $0.02-36.00$ & $2.71-50.10$ & $1.13-27.40$ \\
\hline \multicolumn{4}{|c|}{ Hair cadmium $(\mu \mathrm{g} / \mathrm{g})$} \\
\hline Median & 0.09 & 0.12 & 0.11 \\
\hline Range & $0.01-0.31$ & $0.06-0.50$ & $0.01-1.41$ \\
\hline \multicolumn{4}{|c|}{ Hair mercury $(\mu \mathrm{g} / \mathrm{g})$} \\
\hline Median & 0.07 & $0.23^{b}$ & $0.38^{c}$ \\
\hline Range & $<0.02-0.72$ & $0.07-0.67$ & $0.02-2.90$ \\
\hline
\end{tabular}

aSD = Standard deviation.

${ }^{b} p<0.05$ - Statistically significant from Kazakhstan using analysis of variance and Bonferroni's tests.

${ }^{c} p<0.001$ - Statistically significant from Kazakhstan using analysis of variance and Bonferroni's tests.

and Pakistan (7, 22-26), and sometimes were even bellow the detectable amount of $0.02 \mu \mathrm{g} / \mathrm{g}$.

The possible contribution of high lead intake to the development of IDA in children from CAR is particularly important as these populations are at a particularly high risk of IDA due to the significantly low intake of dietary iron, combined with the high intake of inhibitors of iron absorption (27). Black tea, which is consumed in large amounts in Central Asia, and which contains polyphenols, has a significant impact on the bioavailability of non haem iron in the body. Tea is traditionally introduced early in the diet and it has been reported that between 21 and $49 \%$ of children aged less than 3 years living in Kazakhstan, Kyrgyzstan and Uzbekistan receive tea (28). The early introduction of cow's milk in these countries, often before 3 months, also contributes to the risk of iron deficiency anaemia in young children as it may cause gastrointestinal blood loss and because this source of iron has a low bioavailability. In addition, fruit and vegetable intake, which are good sources of vitamin C, is low in CAR (29). Relatively low concentrations of mercury in children from our study can be explained by low fish consumption in all three countries $(29,30)$, because usually fish is a main vector which mostly contributes to the burden of mercury $(22,24)$.

\section{CONCLUSIONS}

This study showed relatively high levels of hair lead in a sample of anaemic children living in Kazakhstan, Kyrgyzstan, and Uzbekistan, using comparison to reference doses (31). Although the pilot study was small and potential confounding by other factors was not assessed, these exploratory analyses suggest that the potential interaction between lead intoxication and iron deficiency in these populations should be investigated further. In countries such as CAR, where the prevalence of childhood IDA is high, each additional risk factor for IDA is important, especially when affecting the general population. Investigating the extent of exposure of the population to lead and other heavy metals using analyses such as hair concentrations might thus shed some light on the relative importance of heavy metal contamination in the region and its contribution to the high risk of IDA. If the levels are found to be high in a significant proportion of the population, it may then be recommended to assess the food chain as a potential environmental source of heavy metal contaminants as well as other possible vectors from the environment. Appropriate interest of local governments could then contribute to management of reducing exposure and its associated health problems.

\section{Acknowledgements}

The field part of the study was supported by the WHO Regional Office for Europe, Department of Nutrition, Physical Activity and Obesity Programme. Laboratory analyses were performed with institutional support of Masaryk University.

\section{Conflict of Interests}

None declared

\section{REFERENCES}

1. de Benoist B, McLean E, Egli I, Cogswell M, editors. Worldwide prevalence of anaemia 1993-2005. WHO Global Database on Anaemia. Geneva: WHO; 2008.

2. World Health Organization. Iron deficiency anaemia: assessment, prevention and control: a guide for programme managers. Geneva: WHO; 2001.

3. Anderson GJ, McLaren GD, editors. Iron physiology and pathophysiology in humans. Nutrition and health. Totowa: Humana Press; 2012.

4. Rokx C, Galloway R, Brown L. Prospects for improving the nutrition situation in Eastern Europe and Central Asia. New York: World Bank; 2001.

5. Michaelsen KF, Weaver L, Branca F, Robertson A. Feeding and nutrition of infants and young children: Guidelines for the WHO European Region, with emphasis on the former Soviet countries. WHO regional publications, European series, no. 87. Copenhagen: WHO Regional Office for Europe; 2000.

6. World Health Organization. Guidance for identifying populations at risk from mercury exposure. Geneva: WHO; 2008. 
7. Spěváčková V, Kratzer K, Čejchanová M, Beneš B. Determination of some metals in biological samples for monitoring purposes. Cent Eur J Public Health. 1997 Dec;5(4):177-9.

8. Wilhelm M, Lombeck I, Hafner D, Ohnesorge FK. Hair lead levels in young children from the F.R.G. J Trace Elem Electrolytes Health Dis. 1989 Sep;3(3):165-70.

9. Kasznia-Kocot J, Zachwieja Z, Chłopicka J, Krośniak M. The content of selected trace elements and heavy metals in the hair of children from Chorzów. Pediatr Pol. 1996 Jan;71(1):31-6. (In Polish.)

10. Chłopicka J, Zachwieja Z, Zagrodzki P, Frydrych J, Słota P, Krośniak M. Lead and cadmium in the hair and blood of children from a highly industrial area in Poland. Biol Trace Elem Res. 1998 Jun;62(3):229-34.

11. Linderholm L, Jakobsson K, Lundh T, Zamir R, Shoeb M, Nahar N, et al. Environmental exposure to POPs and heavy metals in urban children from Dhaka, Bangladesh. J Environ Monit. 2011 Oct;13(10):2728-34.

12. Komatsu F, Kagawa Y, Kawabata T, Kaneko Y, Chimedregzen U, Purvee $\mathrm{B}$, et al. A high accumulation of hair minerals in Mongolian people: 2(nd) report; influence of manganese, iron, lead, cadmium and aluminum to oxidative stress, Parkinsonism and arthritis. Curr Aging Sci. 2011 Feb;4(1):42-56

13. Rahman MA, Rahman B, Ahmad MS, Blann A, Ahmed N. Blood and hair lead in children with different extents of iron deficiency in Karachi. Environ Res. 2012 Oct;118:94-100.

14. Shah F, Kazi TG, Afridi HI, Kazi N, Baig JA, Shah AQ, et al. Evaluation of status of trace and toxic metals in biological samples (scalp hair, blood, and urine) of normal and anemic children of two age groups. Biol Trace Elem Res. 2011 Jun;141(1-3):131-49.

15. Fraga CG. Relevance, essentiality and toxicity of trace elements in human health. Mol Aspects Med. 2005 Aug-Oct;26(4-5):235-44.

16. Horton LM, Mortensen ME, Iossifova Y, Wald MM, Burgess P. What do we know of childhood exposures to metals (arsenic, cadmium, lead, and mercury) in emerging market countries? Int J Pediatr. 2013;2013:872596.

17. Chan IH, Kong AP, Leung TF, Tsui TK, Cheung RC, Osaki R, et al. Cadmium and lead in Hong Kong school children. Pathology. 2012 Dec;44(7):626-31.

18. Serdar MA, Akin BS, Razi C, Akin O, Tokgoz S, Kenar L, et al. The correlation between smoking status of family members and concentrations of toxic trace elements in the hair of children. Biol Trace Elem Res. 2012 Jul;148(1):11-7.
19. Hrubá F, Strömberg U, Černá M, Chen C, Harari F, Harari R, et al. Blood cadmium, mercury, and lead in children: an international comparison of cities in six European countries, and China, Ecuador, and Morocco. Environ Int. 2012 May;41:29-34.

20. Goudarzi MA, Parsaei P, Nayebpour F, Rahimi E. Determination of mercury, cadmium and lead in human milk in Iran. Toxicol Ind Health. 2013 Oct;29(9):820-3

21. Barton HJ. Advantages of the use of deciduous teeth, hair, and blood analysis for lead and cadmium bio-monitoring in children. A study of 6-year-old children from Krakow (Poland). Biol Trace Elem Res. 2011 Nov; 143(2):637-58.

22. Kruzikova K, Kensova R, Blahova J, Harustiakova D, Svobodova Z. Using human hair as an indicator for exposure to mercury. Neuro Endocrinol Lett. 2009;30 Suppl 1:177-81.

23. Díez S, Esbrí JM, Tobias A, Higueras P, Martínez-Coronado A. Determinants of exposure to mercury in hair from inhabitants of the largest mercury mine in the world. Chemosphere. $2011 \mathrm{Jul} ; 84(5): 571-7$.

24. Liu X, Cheng J, Song Y, Honda S, Wang L, Liu Z, et al. Mercury concentration in hair samples from Chinese people in coastal cities. J Environ Sci (China). 2008;20(10):1258-62.

25. Kim SA, Jeon CK, Paek DM. Hair mercury concentrations of children and mothers in Korea: implication for exposure and evaluation. Sci Total Environ. 2008 Aug 25;402(1):36-42.

26. Anwar M, Ando T, Maaz A, Ghani S, Munir M, Qureshi IU, et al. Scalp hair mercury concentrations in Pakistan. Environ Sci. 2007;14(4):167-75.

27. Yip R. Prevention and control of iron deficiency: policy and strategy issues. J Nutr. 2002 Apr;132(4 Suppl):802S-5S.

28. Gleason GR, Sharmanov T. Anemia prevention and control in four central Asian republics and Kazakhstan. J Nutr. 2002 Apr;132(4 Suppl):867S$70 \mathrm{~S}$

29. FAOSTAT [Internet]. Rome: FAO; (C) 2013 [cited 2014 Mar 4]. Available from: http://faostat.fao.org/site/291/default.aspx.

30. U. S. Environmental Protection Agency. A Review of the reference dose and reference concentration processes. Washington, DC: US EPA; 2002.

Received January 6, 2014 Accepted in revised form March 4, 2014 